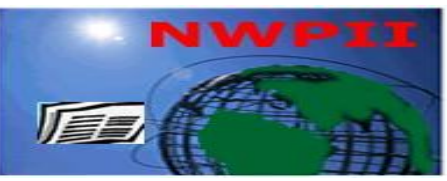

American Journal of Biomedical Sciences

ISSN: 1937-9080

nwpii.com/ajbms

\title{
Age-based Study of Postprandial Lipemia in Hypertensives and Cigarette Smokers
}

\author{
Sajida Rahman ${ }^{1}$, Gaffar Sarwar Zaman ${ }^{2 *}$, Jalelur Rahman ${ }^{3}$ \\ ${ }^{1}$ Department of Clinical Biochemistry, Prathima Institute of Medical Sciences, Karimnagar, Andhra Pradesh, India \\ ${ }^{2}$ Department of Clinical Biochemistry, College of Medicine, King Khalid University, Abha, Saudi Arabia \\ ${ }^{3}$ Department of E.N.T., Prathima Institute of Medical Sciences, Karimnagar, Andhra Pradesh, India \\ Corresponding author: \\ Dr. Gaffar Sarwar Zaman, M.D. \\ Assistant Professor \\ Department of Clinical Biochemistry \\ College of Medicine, King Khalid University \\ Abha, Kingdom of Saudi Arabia \\ Tel: (0) 509228143 \\ Email: gffrzaman@gmail.com; gaffarzaman@rediffmail.com
}

Received: 25 September 2011; | Revised: 8 October 2011; | Accepted: 14 October 2011

\begin{abstract}
Background and Objective: In this review, we have mainly examined the effect of age, smoking and hypertension on post prandial triglycerides, since an exaggerated postprandial accumulation of triglyceride promotes the development of atherosclerosis. This study was designed to test the hypothesis that smoking and hypertension are independently associated with postprandial hypertriglyceridemia and indirectly associated with atherosclerosis.

Materials and methods: Lipid profiles were studied in 52 hypertensives, 48 smokers and 52 age, sex and body mass index matched healthy controls. Four age groups were made between 31-70 years. Fasting and postprandial triglyceridemia were determined sequentially at fasting and at $1 \mathrm{hr}, 2 \mathrm{hr}, 3 \mathrm{hr}, 4 \mathrm{hr}, 5 \mathrm{hr}$ and $6 \mathrm{hr}$ post load in the blood sample.

Results: The repeated-measures analysis of triglyceride levels showed a distinct behavior of the age groups throughout the 6 hours in both controls and cases. The differences in behavior were significant $(p<0.05)$. Total cholesterol, low density lipoprotein cholesterol, high density lipoprotein cholesterol and fasting triglycerides did not differ much significantly over time between the groups. However, the postprandial plasma triglyceride concentration $(\mathrm{mg} / \mathrm{dL})$ increased significantly in hypertensives $(226.5 \pm 82.9)$ and smokers (210.6 \pm 71.8$)$ compared to control group (152 \pm 56.9$), p<0.05$. Increase in postprandial triglycerides was found with age and a positive correlation was found between increase in fasting triglycerides and post prandial triglycerides.

Conclusion: Aging, hypertension and smoking has a significant effect on postprandial lipemia in healthy, young individuals revealing a close link between aging, hypertension, smoking, post prandial triglycerides and atherosclerosis.
\end{abstract}


Keywords: Age, fasting triglyceride, hypertension, post prandial triglyceride, smoking.

\section{Introduction}

Cigarette smoking increases the oxidative modification of low density lipoprotein (LDL-C) with circulating products of lipid peroxidation and levels of oxidized LDL-C found to be significantly increased in both active and passive smokers [1,2]. Epidemiological and laboratory evidence has indicated that smoking decreases plasma high lipoprotein levels (HDL-C) and alters the ratios between HDL-C and LDL-C, HDL-C and triglycerides (TG) and HDL-C and total cholesterol (TC) levels, both in animal models and humans [3,4]. Nicotine stimulates sympathetic adrenal system leading to increased secretion of catecholamines resulting in increased lipolysis and increased concentration of plasma free fatty acids (FFA) which further result in increased secretion of hepatic FFAs and hepatic TG along with very low density lipoproteins (VLDL-C) in the blood stream $[5,6]$. Some studies have reported that TG are not components of the atherosclerotic plaques, but TG-rich lipoproteins are believed to participate directly or indirectly, or both, in atherosclerosis, due to the link between their metabolism and that of the LDL-C and HDL-C, which are known to be related to the atherosclerotic process. The direct participation of intact chylomicrons in the process has been ruled out because of their large diameter, but the participation of their remnants, as first suggested by Zilversmit [7], has gained the support of experimental studies [8,9], The association of aging and atherosclerosis is also relevant, the mechanism of the latter could be partly explained by the influence of age on postprandial lipemia (PPL) [10]. The TG rich lipoproteins are involved in many pathways leading to atherosclerosis. They are carriers of cholesteryl esters to the vessel wall [11] and they are toxic to the endothelial cells and induce endothelial dysfunction [12-15]. More and more research suggests that post prandial hypertriglyceridemia (PPHTG), not fasting hypertriglyceridemia (FHTG), is an independent atherosclerotic disease risk factor [16]. Endothelial cell (EC) damage or dysfunction is associated with the onset and progression of atherosclerosis $[17,18]$. Further injury may lead to plaque destabilization and an acute coronary syndrome. A myriad of seemingly unrelated risk factors may cause EC damage, leading to atherosclerosis. Dyslipidemia has been accorded a crucial role, but our understanding of the contribution of different lipids and lipoproteins continues to evolve $[19,20]$. Recent studies have shown that post-prandial handling of TG rich lipoprotein is important for the propensity of endothelial dysfunction and atherosclerosis [21-23]. Very few data exists regarding the response of post prandial triglycerides (PPTG) in patients with smoking and essential hypertension whose baseline lipid values are within the normal range. This hospital based study was undertaken with the following objectives:

1. To find out the association of PPHTG with age, hypertension and cigarette smoking.

2. To find the association of FTG levels with PPTG levels in hypertensives and cigarette smokers.

\section{Materials and Methods}

\subsection{Patients}

A total of 100 patients (52 hypertensives and 48 smokers) in the age group of 31-70 years were recruited. The Study was designed as a case control study.

Inclusion criteria: The hypertensive patients recruited had a negative CAD history and a history of hypertension based on several separate documented blood pressure measurements above 140/90 $\mathrm{mm} \mathrm{Hg}$ and the use of antihypertensive medications for at least six months' duration. Smoking status was based on the cigarette consumption in the year before the examination. The Controls consisted of 52 normotensive subjects who were free of any disease and had negative family histories for early atherosclerosis and hypertension. They had normal blood pressure (BP) after three measurements.

Exclusion criteria: The patients with hyperlipidemia who were being treated with 
drugs or lipid-lowering therapy. People with diabetes mellitus (DM), obesity, TG $>150 \mathrm{mg} / \mathrm{dL}$ and nephritic range of proteinuria were excluded. Other exclusion criteria were HIV-positive status, overt liver and renal disease. Alcohol consumption and the use of hormonal substitutive treatment (in women) were assessed by questionnaire and excluded. The study was approved by the Ethics Committee of the hospital and all subjects gave written informed consent. Prior to the study, participants were informed that their confidentiality would be maintained and consent was obtained.

\subsection{Preparation of patients and sample collection}

In order to unify food intake the evening before the study, all patients followed written instructions with regard to a standardized dinner composition (Known amount of vegetables and chicken curry with given quantity of rice). They were instructed to eat it before 21:00 hours to avoid the effects of previous food intake and then refrained from all food and beverages (except water) until 08:30 hours on the following morning. On the morning of the visit compliance with dinner instructions was verified with a questionnaire. On the next day, all participants had to be at the laboratory around 08:30 AM and remain at rest without ingesting any type of food, except the standard meal and water. The meal was ingested in up to 15 minutes and comprised sandwich loaf (2 slices equivalent to $140 \mathrm{~g}$ ) and butter (about 20g).

On the day of the study, each participant underwent a structured examination, which included an interview. Data was collected for age, sex, personal past history of DM, hypertension, waist circumference, weight and height to calculate the body mass index (BMI), history of smoking and cerebrovascular accidents. Smoking habits and a familial history of IHD or CVD were assessed by a questionnaire. Height, weight, waist circumference (WC), hip measurements and fasting venipuncture. Height and weight were measured to the nearest $0.5 \mathrm{~cm}$ and $0.1 \mathrm{~kg}$, respectively. BMI was calculated as weight $(\mathrm{kg})$ divided by height (m) squared. WC was determined to the nearest $0.1 \mathrm{~cm}$ using a measuring tape positioned at the midpoint between the lowest rib and the iliac crest and hips were measured at the largest gluteal circumference. These measurements were used to calculate waist-to-hip ratio (WHR). Then BP measurement was done using standard mercury sphygmomanometer. An average of three readings measured thrice at an interval of 15 minutes was taken with subjects in a sitting position. The average of three measurements of Korotkoff phase I was considered as systolic BP, and the average of three values of phase IV was recorded for diastolic BP [24]. Blood samples were collected from the subjects after a 12 hour fast. Samples were centrifuged; serum was collected and stored at $20^{\circ} \mathrm{C}$ until analyzed. Lipid profiles comprising TC, HDL-C, LDL-C and TG concentrations were measured at fasting (F) and at $1 \mathrm{hr}, 2 \mathrm{hr}, 3 \mathrm{hr}, 4 \mathrm{hr}$, $5 \mathrm{hr}$ and $6 \mathrm{hr}$ post-load. Sample serum concentrations of TC, HDL-C and TG were measured by enzymatic colorimetric methods using Star Plus 21 semi-autoanalyser of Rapid Diagnostic Company. Calculation of LDL-C concentrations was based on the Friedewald equation [25]. Estimation of fasting and post prandial plasma glucose (FPG and PPPG) levels were carried out using the Star Plus 21 semiautoanalyser of Rapid Diagnostic Company to exclude diabetes mellitus. Kidney diseases were excluded by measuring serum creatinine and blood urea levels. The diagnosis of DM was based on WHO criteria [26] i.e.: a FPG level $\geq 7.0 \mathrm{mmol} / \mathrm{L}$ or $\geq 126 \mathrm{mg} / \mathrm{dL}$, or a 2 -hour PPPG level $\geq 11.1$ $\mathrm{mmol} / \mathrm{L}$ or $>200 \mathrm{mg} / \mathrm{dL}$ on more than one occasion, with symptoms of diabetes. Liver disease and nephritic range of proteinuria were excluded with the help of liver function tests and HIV test was done to exclude HIV positives.

\subsection{Statistical analysis}

All data were entered into an Excel spreadsheet and were analyzed using standard statistical software like SPSS. Chi square test was used for categorical variables. All numerical data was presented as mean \pm standard deviation. A $p$ value of less than 0.05 was considered statistically significant. 


\section{Results}

The anthropometric measurements and clinical characteristics of the groups of patients and the control subjects are summarized in table 1 . Controls $(n=52)$, smokers $(n=48)$ and hypertensives $(n=52)$ were matched for age, BMI
$($ mean $\pm \mathrm{SD}=27.1 \pm 2.9$ vs. $28.3 \pm 3.1$ vs. $27.7 \pm 2.9$ $\mathrm{kg} / \mathrm{m}^{2}$ respectively), $\mathrm{WC}($ mean $\pm \mathrm{SD}=94.1 \pm 11.6$ vs. $93.4 \pm 8.7$ vs. $94.2 \pm 1.9 \mathrm{~cm}$ respectively) and WHR $($ mean $\pm \mathrm{SD}=0.91 \pm 0.09$ vs. $0.93 \pm 0.04$ vs. $0.92 \pm 0.07$ respectively). The maximum number of people in both the cases (27.8\%) and controls (26.4\%) were in the 51-60 years age group.

Table 1: Anthropometric measurements and age of the smokers, hypertensives and control subjects

\begin{tabular}{|l|c|c|c|}
\hline & Controls $($ mean \pm SD) & Smokers $($ mean \pm SD) & Hypertensives $($ mean \pm SD) \\
\hline BMI $\left(\mathrm{kg} / \mathrm{m}^{2}\right)$ & $27.1 \pm 2.9$ & $28.3 \pm 3.1$ & $27.7 \pm 2.9$ \\
\hline WC $(\mathrm{cm})$ & $94.1 \pm 11.6$ & $93.4 \pm 8.7$ & $94.2 \pm 1.9$ \\
\hline WHR & $0.91 \pm 0.09$ & $0.93 \pm 0.04$ & $0.92 \pm 0.07$ \\
\hline
\end{tabular}

*BMI: body mass index

*WC: waist circumference

*WHR: waist-to-hip ratio

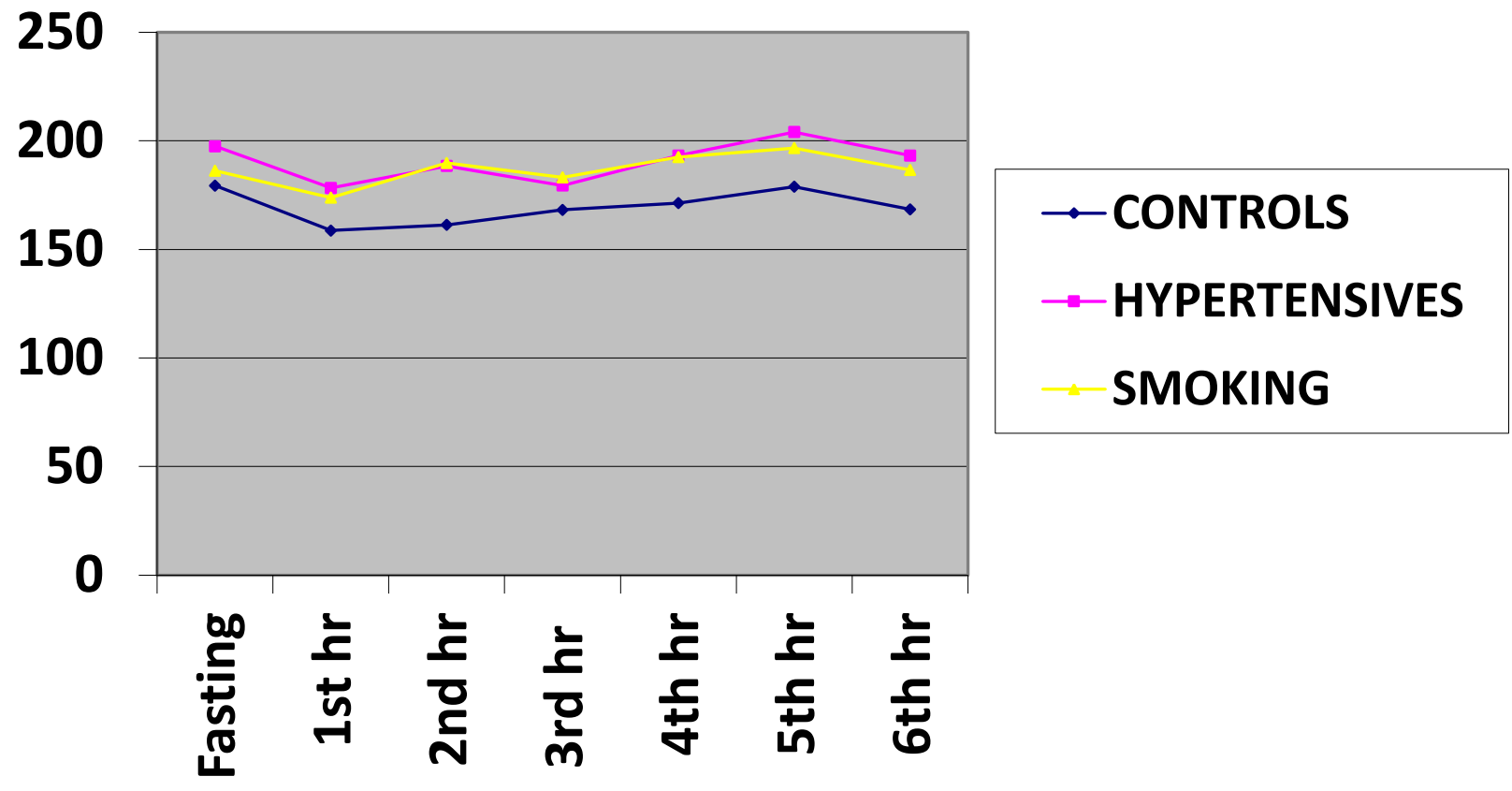

Figure 1- Fasting and postprandial serum cholesterol in $\mathrm{mg} / \mathrm{dL}$ in controls, hypertensives and smokers.

The result of the study on the relationship between serum lipids in controls, hypertensives and smokers are represented in fig. $1-4$. The mean TC in $\mathrm{mg} / \mathrm{dL}$ was $179.37,158.67,161.33,168.2$, 171.36, 178.9 and 168.44 at fasting, 1, 2, 3, 4, 5 and 6 hours in the controls vs. 197.50, 178.3,
188.48, 179.48, 204.11 and 193.23 in the hypertensives during the same duration, while it was $186.26,173.86,189.78,183.17,192.54,196.7$ and 186.6 in the smokers. Cholesterol concentrations showed a significant reduction after $5 \mathrm{hr}$, to reach values similar to baseline after 
$6 \mathrm{~h}$ in hypertensives and smokers but not in controls. The mean HDL-C in $\mathrm{mg} / \mathrm{dL}$ was 48.34 , $44.78,42.15,43.23,41.85,40.7$ and 40.2 at fasting, $1^{\text {st }}, 2^{\text {nd }}, 3^{\text {rd }}$ and $4^{\text {th }}$ hrs after the test meal in the controls vs. 43.39, 42.86, 41.67, 43.28, 41.63, 38.8 and 37.6 in the hypertensives during the same time interval; the HDL-C (in $\mathrm{mg} / \mathrm{dL}$ ) in smokers was found to be 44.68, 43.28, 41.79, 40.86, 41.63, 40.44 and 38.6 during the same time sequence. This shows that HDL-C concentration was decreased more in hypertensives and smokers compared to controls but it was not significant. The mean LDL-C in $\mathrm{mg} / \mathrm{dL}$ was $111.76,117.27$, 96.39, 91.27, 82.83, 88.9 and 95.8 at fasting, 1, 2, $3,4,5$ and 6 hours in the controls vs. 130.51, $125.38,116.50,118.38,114.15,118.2$ and 120.2 in the hypertensives during the same amount of time; smokers had LDL-C values (in $\mathrm{mg} / \mathrm{dL}$ ) of $132.47,127.64,121.46,117.64,110.51,114.6$ and 119.2 during the same. The comparison of TG between controls and hypertensives, and, controls and smokers really showed a significant difference $(p<0.05)$. The mean TG in $\mathrm{mg} / \mathrm{dL}$ was 115.35 , $123.43,152.63,165.21,189.55,201.4$ and 210.22 at fasting, 1, 2, 3, 4, 5 and 6 hours in the controls whilst it was 160.36, 188.38, 205.54, 243.43, $256.59,274.9$ and 286.4 in the hypertensives during the same duration; also in smokers it (TG) was $164.47 \mathrm{mg} / \mathrm{dL}, 183.27 \mathrm{mg} / \mathrm{dL}, 199.37 \mathrm{mg} / \mathrm{dL}$, $223.66 \mathrm{mg} / \mathrm{dL}, 243.24 \mathrm{mg} / \mathrm{dL}, 268.5 \mathrm{mg} / \mathrm{dL}$ and $288.6 \mathrm{mg} / \mathrm{dL}$.

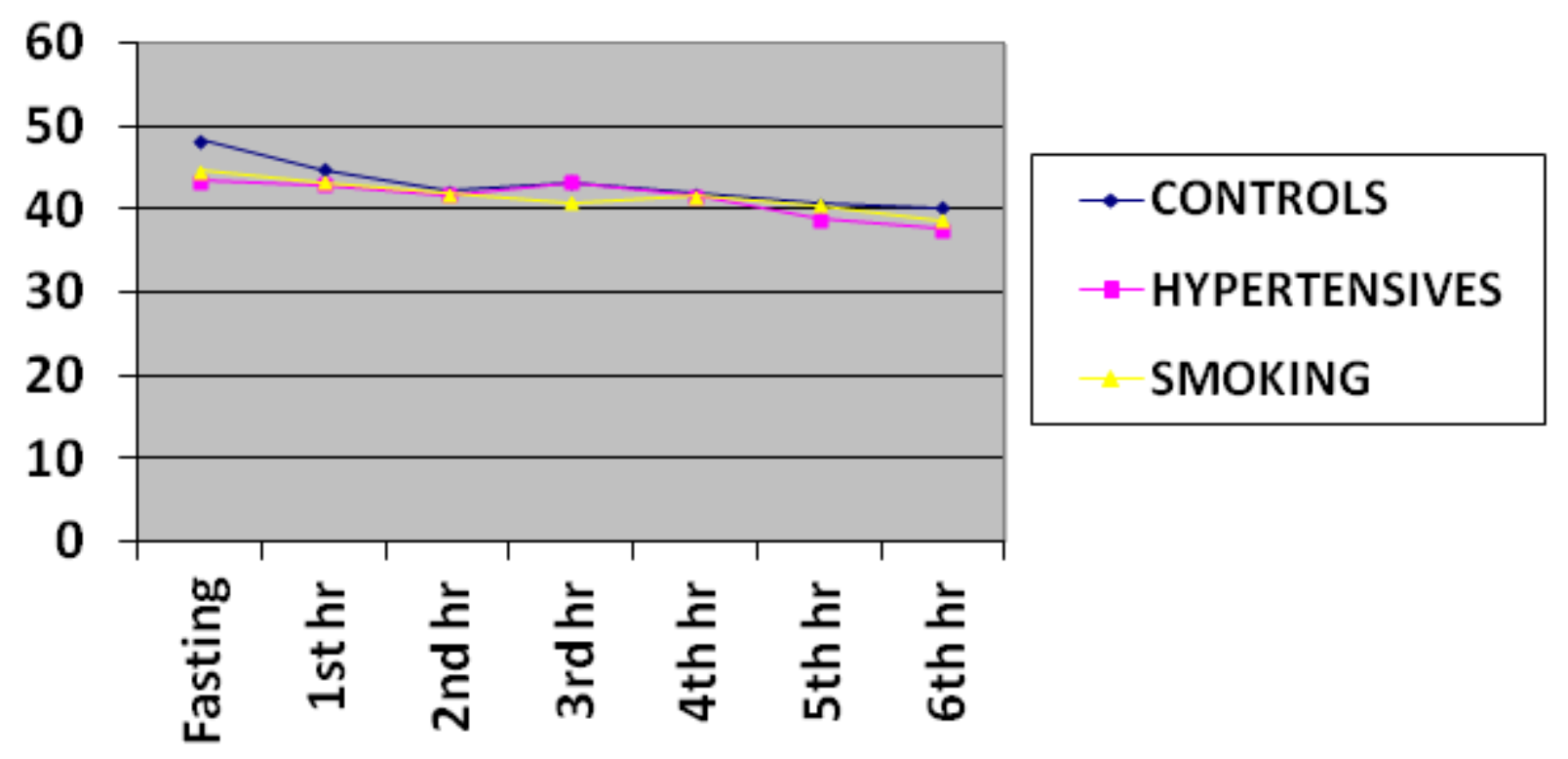

Figure 2 - Fasting and postprandial serum HDL-Cholesterol in mg/dL in controls, hypertensives and smokers.

Analysis of each age group throughout time for PPTG showed significant differences in the means in almost all groups. In controls the mean PPTG in G-I in $\mathrm{mg} / \mathrm{dL}$ was $141 \pm 18$, G-II

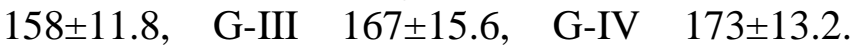
Similarly in smokers, the PPTG in $\mathrm{mg} / \mathrm{dL}$ in various groups were respectively $172 \pm 9.3$ in G-I, $180 \pm 19.7$ in G-II, $202 \pm 18.4$ in G-III and $214 \pm 47$ in G-IV as shown in table 2. Likewise, in hypertensives the PPTG in $\mathrm{mg} / \mathrm{dL}$ in various groups were respectively $176 \pm 14.1$ in G-I,
$183 \pm 28.8$ in G-II, $204 \pm 27.1$ in G-III and $239 \pm 56$ in G-IV as shown in table 2. Also influence of time was seen between controls and hypertensives and controls and smokers regarding PPTG. Almost every hour increase in the PPTG levels was seen in smokers and hypertensives compared to controls.

Fasting lipid profiles showed that patients with hypertension had slightly elevated mean TC, LDL-C and TG levels and lower HDL-C concentrations than the control subjects, but not 
significantly so. The mean PPTG in $\mathrm{mg} / \mathrm{dL}$ was $226.5 \pm 82.9 \quad$ v/s $\quad 152 \pm 56.9 \quad(p<0.05) \quad$ in hypertensives and controls, and $210.6 \pm 71.8 \mathrm{v} / \mathrm{s}$ $152 \pm 56.9(p<0.05)$ in smokers and controls, and respectively. Significant differences were found between the three groups before and after the fat load $(p<0.05)$.

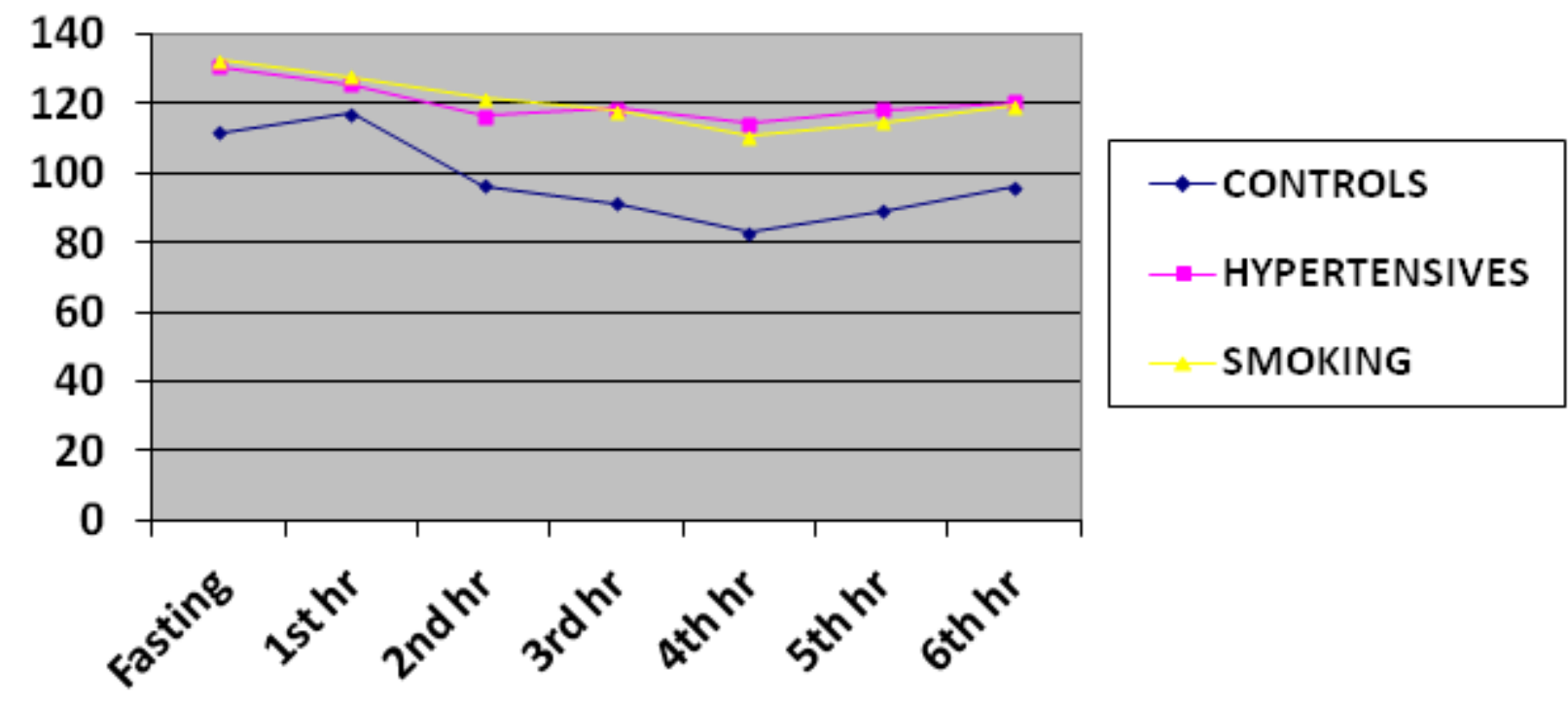

Figure 3 - Fasting and postprandial serum LDL-Cholesterol in $\mathrm{mg} / \mathrm{dL}$ in controls, hypertensives and smokers.

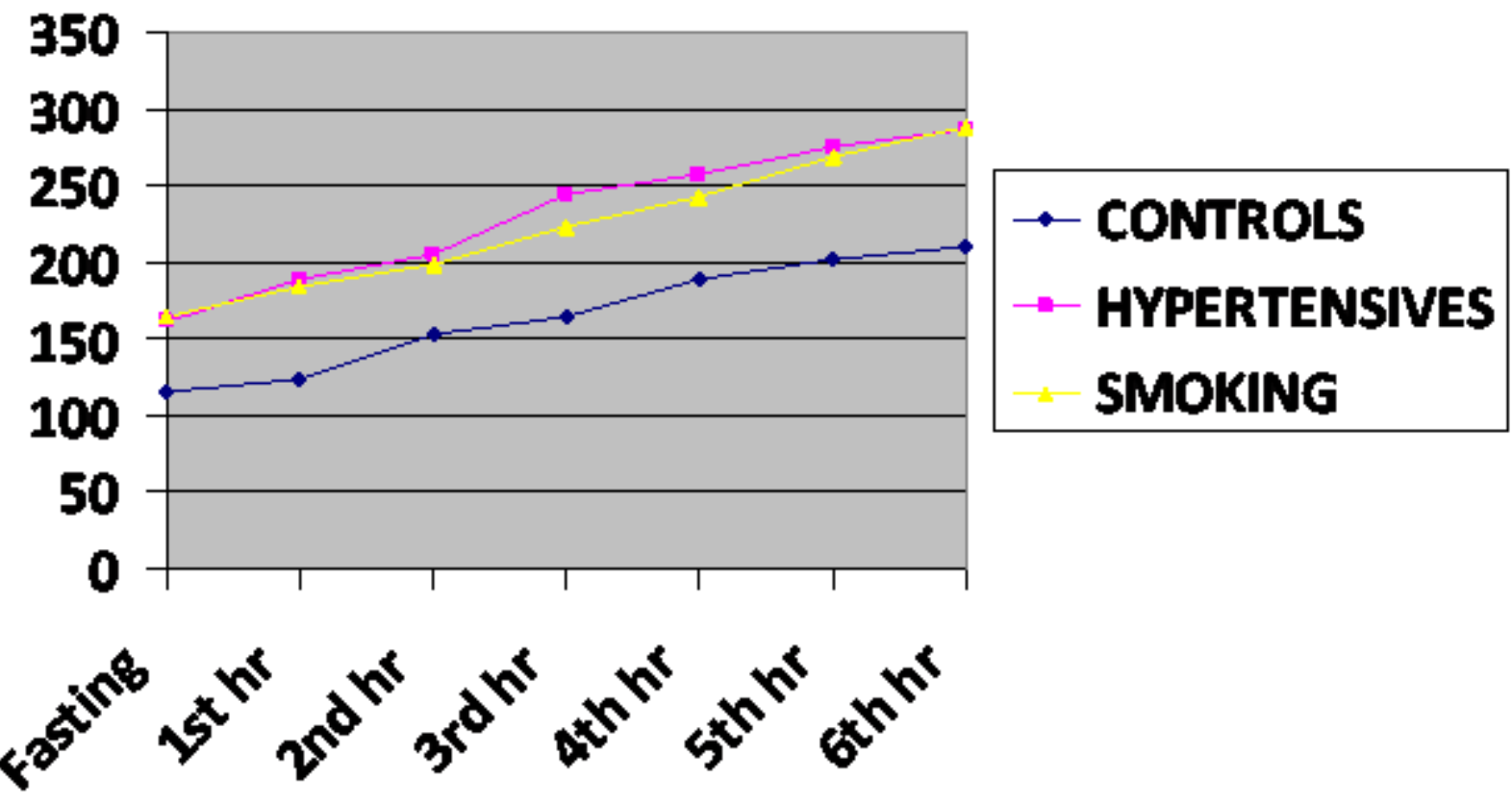

Figure 4 - Fasting and postprandial serum triglyceride in $\mathrm{mg} / \mathrm{dL}$ in controls, hypertensives and smokers. 
Table 2: Laboratory characteristics of the fasting and post-prandial triglyceride sample and age groups.

\begin{tabular}{|c|c|c|c|c|c|c|c|}
\hline \multicolumn{1}{|c|}{$\begin{array}{c}\text { Variable } \\
(\mathrm{mg} / \mathrm{dL})\end{array}$} & Total sample & $\begin{array}{c}\text { G-I } \\
31-40 \\
\text { years }\end{array}$ & $\begin{array}{c}\text { G-II } \\
41-50 \\
\text { years }\end{array}$ & $\begin{array}{c}\text { G-III } \\
51-60 \\
\text { years }\end{array}$ & $\begin{array}{c}\text { G-IV } \\
61-70 \\
\text { years }\end{array}$ & $p$ value \\
\hline \multirow{2}{*}{$\begin{array}{l}\text { Fasting } \\
\text { Triglycerides }\end{array}$} & Controls & $98.32 \pm 36.8$ & $70 \pm 7.4$ & $87.6 \pm 9.8$ & $110 \pm 7.6$ & $118 \pm 9.1$ & $p<0.05$ \\
\cline { 2 - 8 } & Hypertensives & $101.32 \pm 43.8$ & $67 \pm 5.8$ & $91.4 \pm 8.6$ & $113 \pm 5.6$ & $117 \pm 10.3$ & $p<0.05$ \\
\cline { 2 - 8 } & Smokers & $99.66 \pm 39.2$ & $66 \pm 9.2$ & $95.2 \pm 2.6$ & $111 \pm 6.3$ & $120 \pm 8.4$ & $p<0.05$ \\
\hline \multirow{2}{*}{$\begin{array}{l}\text { Post Prandial } \\
\text { Triglycerides }\end{array}$} & Controls & $152 \pm 56.9$ & $141 \pm 18$ & $158 \pm 11.8$ & $167 \pm 15.6$ & $173 \pm 13.2$ & $p<0.05$ \\
\cline { 2 - 8 } & Hypertensives & $226.5 \pm 82.9$ & $176 \pm 14.1$ & $183 \pm 28.8$ & $204 \pm 27.1$ & $239 \pm 36$ & $p<0.05$ \\
\cline { 2 - 8 } & Smokers & $210.6 \pm 71.8$ & $172 \pm 9.3$ & $180 \pm 19.7$ & $202 \pm 18.4$ & $214 \pm 27$ & $p<0.05$ \\
\hline
\end{tabular}

\section{Discussion}

There have been many studies to find out the relationship between postprandial hyperlipidemia, CAD [27-29], smoking and influence of age. The results obtained in the assessment of TG showed that the behavior of PPL was different in the different age groups. The differences found could be attributed to the gastric emptying time or intestinal absorption, or both. Some studies have shown that the gastric emptying of liquids and solids decreases with age [30], but intestinal motility is not altered with age [31]. Pancreatic secretion slightly decreases with age [32]. However, Arora et al [33] studying [34] healthy individuals have reported that fecal excretion, and, consequently, fat absorption changes slightly with age, suggesting that the decrease in pancreatic secretion is not enough to hinder the normal digestive process. One could imagine that because older individuals have a longer gastric emptying time, the absorption of fat would be slowed, justifying a late elevation in triglyceridemia. The metabolic alterations were caused by the standardized meal with a relatively low fat content (40 g, 50\% being saturated fat) if compared with studies assessing PPL by using a standardized meal with a high fat content (70 g). Such findings stress the need for adopting preventive measures in early age groups, with fat consumption restricted to a maximum of $30 \%$ of the total caloric value, and saturated fat consumption restricted to $7 \%$ of that value, as recommended by the current guidelines for prevention of cardiovascular diseases $[35,36]$. In conclusion, aging has a significant effect on PPL in healthy, young individuals. It was found in the present study that hypertensive patients had increased PPTG levels $(226.5 \pm 82.9 \mathrm{mg} / \mathrm{dL})$, compared to the controls $(152 \pm 56.9 \mathrm{mg} / \mathrm{dL})$ who had no significant increase in the same duration. There were no significant difference in the HDL-C, LDL-C and FTG levels in the two groups. It has been suggested that essential hypertension is a strong risk factor for CAD. Insulin resistance is associated with hypertension. Hyperinsulinemia usually induces an overproduction of TG-rich lipoproteins in the liver by increasing the availability of free fatty acids, which are the most important precursors of de novo TG synthesis. But it has been seen that the postprandial response is complex, and both lipoprotein concentrations and composition are affected [37]. Data collected over 25 years ago from the Framingham Heart Study demonstrated that TG levels could influence the CAD risk only in patients with a low HDL-C concentration [38]. After numerous reports, the association of high TG concentration with low HDL-C levels is now well established among patients with CAD [39]. Obesity is also associated with higher TG concentrations [40], and interactions between obesity on plasma TG have been reported [41]. Therefore obese individuals were excluded in our study. On the other hand, essential hypertension is characterized by a defect of endothelial nitric oxide synthesis [42]. A single gene defect [43] or the polymorphism of endothelial nitric oxide synthase gene [44]. Other factors besides $\mathrm{TG}$ that have a further influence on HDL-C levels are BMI, adipose tissue distribution, serum glucose and insulin levels, smoking and alcohol intake [45,46]. An increase 
in postprandial levels of TC, LDL-C, VLDL-C, and TG were seen, while a significant fall in average level of HDL-C was seen in smokers as compared to that in non-smokers. Mean postprandial level of serum TG levels in smokers were significantly high $(210.6 \pm 71.8 \mathrm{mg} / \mathrm{dL}$ $(p<0.05)$, compared to controls $(152 \pm 56.9 \mathrm{mg} / \mathrm{dL})$. Most of the smokers had been smoking for a mean duration of 8 years.

\section{Conclusion}

In summary we conclude that aging, hypertension and smoking has a significant effect on PPL in healthy, young individuals revealing a close link between aging, hypertension, smoking, PPTG and atherosclerosis.

\section{References}

1. Panagiotakos, D.B.; Pitsavos, C.; et al. ATTICA study. Effect of exposure to secondhand smoke on markers of inflammation: the ATTICA study. Am. J. Med. 2004,116,145-50. DOI:10.1016/j.amjmed. 2003.07.019

2. Heitzer, T.; Ylä-Herttuala, S; Luoma, J.; et al. Cigarette smoking potentiates endothelial dysfunction of forearm resistance vessels in patients with hypercholesterolemia. Role of oxidized LDL. Circulation 1996, 93, 1346-53. DOI: 10.1161/01.CIR.93.7.1346

3. Yuan, H.; Wong, L.S.; Bhattacharya, M.; et al. The effects of second-hand smoke on biological processes important in atherogenesis. BMC Cardiovasc. Disord. 2007, 7, 1. DOI: 10.1186/1471-2261-7-1

4. Ambrose, J.A.; Barua, R.S. The pathophysiology of cigarette smoking and cardiovascular disease: an update. J. Am. Coll. Cardiol. 2004, 43,1731-7. DOI:10.1016/j.jacc. 2003.12.047

5. Muscat, J.E.; Harris, R.E.; et al. Cigarette smoking and plasma cholesterol. Am Heart J 1991, 121, 141-7. DOI:10.1016/00028703(91)90967-M

6. Simons, L.A.; Simons, J.; Jones, A.S. The interaction of body weight, age, cigarette smoking and hormone usage with blood pressure and plasma lipids in an Australian community. Aus NZ J Med 1984, 14, 215-21. DOI: 10.1111/j.1445-5994.1984.tb03753.x

7. Zilversmit, D.B. Atherogenesis: A postprandial phenomenon. Circulation 1979, 60, 473-85. DOI:10.1161/01.CIR.60.3.473

8. Mamo, J.C.L.; Wheeler, J.R. Chylomicrons or their remnants penetrate rabbit thoracic aorta as efficiently as do smaller macromolecules, including low-density lipoprotein, high density lipoprotein and albumin. Coron. Artery Dis 1994, 5, 695-705.

9. Proctor, S.D.; Mamo, J.C.L. Arterial fatty lesions have increased uptake of chylomicrons remnants but not low-density lipoproteins. Coron. Artery Dis 1996, 7, 239-46.

10. Jaqueline, S.I.; Jayme, D. Neusa Forti Postprandial Lipemia: Influence of Aging. Arquivos Brasileiros de Cardiologia 2005, 85, 86-94. DOI.org/10.1590/S0066-782X2005001 400004

11. University College London Medical School: Hypertriglyceridaemia and vascular risk. Report of a meeting of physicians and scientists. Lancet 1993, 342, 781-787. DOI:10.1016/0140-6736(93)91544-V

12. Funada, J.; Sekiya, M.; Hamada, M; Hiwada, K. Postprandial elevation of remnant lipoprotein leads to endothelial dysfunction. Circ J 2002, 66, 127-132. DOI:10.1253/circj.66.127

13. Jagla, A.; Schrezenmeir, J. Postprandial triglycerides and endothelial function. Exp Clin Endocrinol Diabetes 2001, 109, S533547. DOI: $10.1055 / \mathrm{s}-2001-15116$

14. Gokce, N.; Duffy, S.J.; Hunter, L.M.; Keaney, J.F.; Vita, J.A. Acute hypertriglyceridemia is associated with peripheral vasodilatation and increased basal flow in healthy young adults. Am J Cardiol 2001, 88, 153-159. PII: S00029149(01)01610-1

15. Bae, J.H.; Bassenge, E.; Kim, Y.N.; et al. Postprandial hypertriglyceridemia impairs endothelial function by enhance oxidant stress. Atherosclerosis 2001, 155, 517-523. PII: S0021-9150(00)00601-8

16. Boquist, S.; Ruotolo, G.; Rong, T.; et al. Alimentary lipemia, postprandial triglyceride- 
rich lipoproteins, and common carotid intimamedia thickness in healthy, middle-aged men. Circulation 1999, 100, 723-728. DOI: 10.1161/01.CIR.100.7.723

17. Libby, P. Current concepts of the pathogenesis of acute coronary syndromes. Circulation. 2001, 104, 365-372. DOI: 10.1161/01.CIR. 104.3.365

18. Libby, P.; Ridkin, P.M.; Maseri, A. Inflammation and atherosclerosis. Circulation 2002, 105, 1135-1143. DOI: 10.1161/hc0902. 104353

19. Libby, P. Vascular biology of atherosclerosis: overview and state of the art. Am J Cardiol. 2003, 91, 3A-6A. DOI:10.1016/S00029149(02)03143-0

20. Ross, R. Cell biology of atherosclerosis. Аnnи Rev Physiol. 1995, 57, 791-804. DOI: 10.1146/annurev.ph.57.030195.004043

21. Patsch, J.R. Triglyceride-rich lipoproteins and atherosclerosis. Atherosclerosis 1994, 110, S23-6. DOI:10.1016/0021-9150(94)05372-P; PII: 0021-9150(94)05372-P

22. Dubois, C.; Armand, M.; Azais-Braesco, V.; et al. Effects of moderate amounts of emulsified dietary fat on postprandial lipemia and lipoproteins in normolipidemic adults. Am J Clin Nutr 1994, 60, 374-82.

23. Lewis, G.F.; O'Meara, N.M.; Soltys, P.A.; et al. Fasting hypertriglyceridemia in noninsulindependent diabetes mellitus is an important predictor of postprandial lipid and lipoprotein abnormalities. J Clin Endocrinol Metab 1991, 72, 934-44. DOI: 10.1210/jcem-72-4-934

24. Fuller, H; Stevens, L.K. Diabetes Hypertension Study Group. Prevalence of hypertension among diabetic patients and it relation to vascular risk. Journal of human hypertension, 1991, 5(4), 237-43.

25. Friedewald, W.T.; Levy, R.I; Frederickson, D.S. Estimation of the concentration of low density lipoprotein cholesterol in plasma, without use of the preparative ultracentrifuge. Clin Chem 1972, 18,499-502.

26. American Diabetes Association. Diagnosis and classification of Diabetes Mellitus. Diabetes Care 2004, 27, S5-10. DOI: 10.2337/diacare. 27.2007.S5
27. Przybycien, K.; Kornacewicz-Jach, Z.; Torbus-Lisiecka, B.; Naruszewicz, M. Is abnormal postprandial lipemia a familial risk factor for coronary artery disease in individuals with normal fasting concentrations of triglycerides and cholesterol? Coronary Artery Dis 2000, 11, 377-381.

28. Hamsten, A.; Bjorkengren, J.; Boquist, S.; et al. Postprandial lipaemia and coronary heart disease. Jacotot B, Mathe' D, Fruchart J-C (eds): "Atherosclerosis XI." New York: Elsevier Science 1998, 11, 141-149.

29. Hennig, B.; Toborek, M.; McClain, C.J. Highenergy diet, fatty acids and endothelial cell function: implications for atherosclerosis. $J$ Am Coll Nutr 2001, 20, 97-105.

30. Evans, M.A.; Triggs, E.J.; Cheung, M.; et al. Gastric emptying rate in elderly: implications for drug therapy. J Am Geriatr Soc 1981, 29, 201-05. PMID: 6262396

31. Kupfer, R.M.; Heppell, M.; Haggith, J.W.; et al. Gastric emptying and small-bowel transit rate in the elderly. J Am Geriatr Soc 1985, 33, 340-03. PMID: 3989199

32. Fikry, M. Exocrine pancreatic functions in the aged. J Am Geriatr Soc 1968, 16, 463-7.

33. Arora, S.; Kassarjian, Z.; Krasinki, S.D.; et al. Effect of age on tests of intestinal and hepatic function in healthy humans. Gastroenterology 1989, 96, 1560-5. PII: 0016-5085(89)90527-1

34. Krasinski, S.D.; Cohn, J.S.; Schaefer, E.J.; et al. Postprandial plasma retinyl ester response is greater in older subjects compared with younger subjects. J Clin Invest 1990, 85, 88392. DOI:10.1172/JCI114515

35. National Cholesterol Education Program (NCEP) Expert Panel on Detection, Evaluation, and Treatment of High Blood Cholesterol in Adults (Adult treatment Panel III) JAMA 2001， 285, 2486-97. DOI: $10.1001 / \mathrm{jama} .285 .19 .2486$

36. Diretrizes Brasileiras sobre Dislipidemias, III. Arq Bras Cardiol 2001, 77(Supl. III), 1- 48. DOI.org/10.1590/S0066-782X2001001500001

37. Genovefa, D. et al. Postprandial Lipemia in Hypertension. Journal of the American College of Nutrition, 2003, 22(1), 80-87. 
38. Castelli, W.P. The triglyceride issue: a view from Framingham. Am Heart J 1986, 112, 432-437.DOI:10.1016/0002-8703(86)90296-6

39. Jeppesen, J.; Hein, H.O.; Suadicani, P.; et al. High triglycerides/low high density lipoprotein cholesterol, ischemic electrocardiogram changes, and risk of ischemic heart disease. Am Heart J 2003, 145, 103-108. DOI:10.1067/mhj.2003.45

40. Dallongeville, J.; Lussier, S.; Davignon, J. Modulation of plasma triglyceride levels by apoE phenotype: a metaanalysis. J Lipid Res. 1992, 33, 447-54.

41. Reznik, Y.; Morello, R.; Pousse, P.; Mahoudeau, J.; Fradin, S. The effect of age, body mass index, and fasting triglyceride level on postprandial lipemia is dependent on apolipoprotein E polymorphism in subjects with non-insulin-dependent diabetes mellitus. Metabolism. 2002, 51, 1088-92. DOI:10.1053/meta.2002.34696

42. Forte, P; Copland, M.; Smith, L.M.; Milne, E.; Sutherland, J.; Benjamin, N. Basal nitric oxide synthesis in essential hypertension. Lancet 1997, 349, 837-842. DOI:10.1016/S0140$\underline{6736(96) 07631-3}$
43. Duplain, H.; Burcelin, R.; Sartori, C.; et al. Insulin resistance, hyperlipidemia, and hypertension in mice lacking endothelial nitric oxide synthase. Circulation 2001, 104, 342345. DOI: 10.1161/01.CIR.104.3.342

44. Chen, W.; Srinivasan, S.R.; Elkasabany, A.; Ellsworth, D.L.; Boerwinkle, E.; Berenso, G.S.; Combined effects of endothelial nitric oxide synthase gene polymorphism (G894T) and insulin resistance in young adults: the Bogalusa Heart Study. Am J Hypertens 2001, 14, 1046-1052. DOI:10.1016/S08957061(01)02192-6

45. Ellison, R.C.; Zhang, Y.; Qureshi, M.M.; et al. Lifestyle determinants of high-density lipoprotein cholesterol: the National Heart, Lung, and Blood Institute Family Heart Study. Am Heart $J$ 2004, 147, 529-535. DOI:10.1016/j.ahj.2003.10.033

46. Goff, D.C. Jr; D’Agostino, R.B.Jr; Haffner, S.M.; et al: Insulin resistance and adiposity influence lipoprotein size and subclass concentrations. Results from the Insulin Resistance Atherosclerosis Study. Metabolism 2005, 54, 264-270. DOI:10.1016/j.metabol. $\underline{2004.09 .002}$ 